\title{
Manufacturing Carbon Material by Carbonization of Cellulosic Palm Oil Waste for Supercapacitor Material
}

\author{
Reza Hendriansyah, Tirto Prakoso*, Pramujo Widiatmoko, Isdiriayani Nurdin, and Hary Devianto \\ Institut Teknologi Bandung, Chemical Engineering Department, Jl. Ganesha 10 40132, Indonesia
}

\begin{abstract}
Palm oil waste as biomass resources in Indonesia were not fully utilized. One of the product that can be made from oil palm biomass is activated carbon. Activated carbon characteristic with high porosity and good conductivity, made activated carbon suitable as supercapacitor electrode material. Activated carbon preparation consists of two main steps that are carbonization and activation. In this research carbonization carried out by hydrothermal process while activation conducted by physcal activation. This research focused on manufacturing activated carbon from palm oil waste by hydrothermal carbonization for supercapacitor application. Activated carbon produced from empty fruit bunch have a surface area of $330-1181 \mathrm{~m}^{2} / \mathrm{gr}$, pore volume of $0.19-0.69 \mathrm{~cm}^{3} / \mathrm{gr}$, and pore size of $2.1-2.3 \mathrm{~nm}$. While activated carbon produced from oil palm shell have surface area of $8-451 \mathrm{~m}^{2} / \mathrm{gr}$, pore volume $0.05-1.064 \mathrm{~cm}^{3} / \mathrm{gr}$, and pore size $2.9-20.7 \mathrm{~nm}$. The crystallinity of the activated carbon obtained ranged from 46.5 to $51.9 \%$. In this study, the activated carbon is used as a working electrode on an asymmetric hybrid supercapacitor with nickel oxide being used as second electrode. This palm oil-based supercapacitor cell has a capacitance of $1.7554 \mathrm{~F} / \mathrm{g}$.
\end{abstract}

\section{Introduction}

Indonesia is the largest palm oil producer (Crude Palm Oil) in the world with palm oil production reaches 30 million tons in 2015. Increasing of Indonesia's palm oil production volumes also produced a high amount of palm oil waste especially biomass. Utilization of oil palm biomass for producing new resources is needed to solve the waste management problem. One of the products that can be produced from palm oil waste biomass is activated carbon. Activated carbon is an amorphous carbon material with high porosity and interparticulate surface area [1]. Activated carbon is usually used as an adsorbent, heterogeneous catalyst support, energy storage applications, etc [2]. Utilization of activated carbon for energy storage applications is used for supercapacitor electrode material due to it has high electrical conductivity, cheap, and easy to produce [2]. Surface area and pore size of activated carbon can be tuned by appropriate method and operating parameters. The pore size of activated carbon which is suitable for capacitor electrode is in the mesopore range $(2-50 \mathrm{~nm})$.

Activated carbon preparation consists of carbonization and activation process. The carbonization process is commonly conducted by pyrolysis method by heating the raw material at temperature range $300-650^{\circ} \mathrm{C}$ with low oxygen condition [3]. Another carbonization process which can be used is a hydrothermal method.
Hydrothermal carbonization is a thermochemical conversion process that uses aqueous media to convert biomass into high-value products. The advantage of the hydrothermal process due to it used lower energy than pyrolysis process because the operation temperature is lower than pyrolysis process. Hydrothermal process carried out at a temperature range of $150-350^{\circ} \mathrm{C}$ [4]. High water content in palm oil biomass waste is suitable for hydrothermal processes because this process does not require the drying process of raw materials [5]. This research was focusing on utilization of palm oil biomass waste to get activated carbon for supercapacitor electrode material using hydrothermal process.

\section{Experimental}

Hydrothermal carbonization was conducted in a hydrothermal reactor while activation process in a tubular furnace. Empty fruit bunch (EFB) and palm oil shell (POS) were chosen as biomass samples. The samples were gathered from PT. Perkebunan Nusantara VIII in Bogor and palm oil plantation in Riau. EFB and POS were cleaned using water and dried. After that, dried biomass is crushed using disc mill and sieved into coarse granules (35-80 mesh).

\footnotetext{
Corresponding author: tirto@,che.itb.ac.id
} 


\subsection{Hydrothermal}

Biomass with the specified ratio of biomass to water (1:10 and $1: 3)$ was fed into hydrothermal reactors containing water mixed with $\mathrm{ZnCl}_{2}$. The ratio of $\mathrm{ZnCl}_{2}$ to the biomass was $2: 1$ and operating temperature at $275^{\circ} \mathrm{C}$. After the reactor reached the desired temperature, it was kept constant for 20-60 minutes. The obtained biochar was then filtered and dried at $105^{\circ} \mathrm{C}$ for 24 hours.

\subsection{Activation}

The biochar which recovered from hydrothermal process loaded onto crucible and positioned inside the tubular furnace. The furnace temperature was raised by $10^{\circ} \mathrm{C} / \mathrm{min}$ to reach $800^{\circ} \mathrm{C}$ under the presence of $\mathrm{N}_{2}$ at a flow rate of $50 \mathrm{ml} / \mathrm{min}$. After the temperature was reached, $\mathrm{N}_{2}$ was replaced with $\mathrm{CO}_{2}$ at a flow rate of 40 $\mathrm{ml} / \mathrm{min}$ for two hours. Afterwards the furnace was cooled to room temperature in the presence of $\mathrm{N}_{2}$. Then, activated carbon was stirred for 30 minutes in $\mathrm{HCl}$ solution $(0,1 \mathrm{M})$. Furthermore, activated carbon was washed with demineralized water until $\mathrm{pH}$ of the wash water reached 7 . The activated carbons were washed and dried at $105^{\circ} \mathrm{C}$ for 24 hours.

\subsection{Characterizations}

Ultimate and proximate analysis conducted in Laboratorium Pengujian Batubara Tekmira Bandung to determine the chemical and physical characteristic of biomass. Fixed carbon content of biochar determined by gravimetric analysis. FTIR analysis was conducted to get the quantitative and qualitative estimation of oxygencontaining-functional groups. Surface area and pore diameter of activated carbon were analyzed by a gas sorption Quantochrome Instruments Nova 3200e in Laboratorium Instrumentasi Teknik Kimia ITB. The crystalline structure of activated carbon was analyzed by X-ray diffraction (XRD) technique using Bruker D8 Advance with $\mathrm{Cu}-\mathrm{K}$ radiation $(\lambda=1.54 \AA)$ conducted in Laboratorium Instrumentasi Teknik Kimia ITB. The morphology of raw materials and activated carbon were examined by Scanning Electron Microscopy (SEM) using SEM Hitachi SU3500 conducted in Pusat Penelitian Nanosains dan Nanoteknologi Institut Teknologi Bandung.

\subsection{Electrochemical characterizations}

The electrochemical analysis was conducted to observed activated carbon performance when assembled as a supercapacitor cells. Cyclic voltammetry (CV), Galvanostatic charge/discharge (GCD), and electrochemical impedance spectroscopy (EIS) were examined using Gamry V3000.

The electrochemical examination was performed by assembling supercapacitor cell in an asymmetrical twoelectrode configuration. The negative electrode was made from activated carbon which placed in $1 \mathrm{~cm}^{2}$ of stainless steel mesh. The positive electrode was made from nickel oxide which placed in $1 \mathrm{~cm}^{2}$ of carbon sheet.
Nafion 212 was sandwiched between two electrodes and then infiltrated with an electrolyte solution $(6 \mathrm{M} \mathrm{KOH})$.

\section{Result and discussion}

\subsection{Biomass characterizations}

Tabel 1. shows the composition of empty fruit bunch and palm oil shell. Biomass composition is depended by where the biomass growth. Based on Table 1, it was the common characteristic of empty fruit bunch and palm oil shell that growth in Indonesia. The ultimate analysis result is observed that both empty fruit bunch and palm oil shell has no significant difference in carbon, hydrogen, nitrogen, oxygen, and sulphur content.

Table 1. The Result of Ultimate and Proximate Analysis of EFB and POS

\begin{tabular}{|c|c|c|}
\hline \multicolumn{3}{|c|}{ Ultimate Analysis (\%) } \\
\hline C & $48.83 \%$ & $47.38 \%$ \\
\hline H & $6.52 \%$ & $5.94 \%$ \\
\hline N & $0.69 \%$ & $0.47 \%$ \\
\hline O & $39.64 \%$ & $43.54 \%$ \\
\hline S & $0.13 \%$ & $0.05 \%$ \\
\hline \multicolumn{3}{|c|}{ Proximate Analysis } \\
\hline M & $5.47 \%$ & $9.01 \%$ \\
\hline VM & $73.17 \%$ & $68.00 \%$ \\
\hline F C & $17.17 \%$ & $20.37 \%$ \\
\hline A & $4.19 \%$ & $2.62 \%$ \\
\hline
\end{tabular}

Fixed carbon and volatile matter content in empty fruit bunch and palm oil shell is high so that this biomass suitable as a precursor material for activated carbon [6]. The difference of fixed carbon content in empty fruit bunch and palm oil shell will affect the fixed carbon yield that remains in biochar after hydrothermal carbonization process.

\subsection{Hydrothermal carbonization}

Table 2. shows the result of gravimetric analysis for determining fixed carbon yield of biochar. From Table 2., the holding time and biomass-to-water ratios do not give any significant effect of fixed carbon yield in biochar. Fixed carbon yield of biochar from empty fruit bunch is around $8 \%$ while from palm oil shell is around $9 \%$. Fixed carbon yield of biochar from palm oil shell is higher than it from empty fruit bunch. This might occur because palm oil shell has higher fix carbon content as shown in Table 1. 
Table 2. Fixed carbon yield of bio-char

\begin{tabular}{|c|c|c|c|}
\hline \multirow{2}{*}{$\begin{array}{c}\text { Raw } \\
\text { Materials }\end{array}$} & \multirow{2}{*}{$\begin{array}{c}\text { Time } \\
(\mathrm{min})\end{array}$} & \multicolumn{2}{|c|}{ Biomass to water ratios } \\
\cline { 2 - 4 } & 20 & $1: 10$ & $1: 3$ \\
\hline \multirow{3}{*}{ EFB } & 40 & $9.63 \%$ & $8.70 \%$ \\
\cline { 2 - 4 } & 60 & $9.30 \%$ & $8.05 \%$ \\
\hline \multirow{3}{*}{ POS } & 20 & $9.15 \%$ & $9.61 \%$ \\
\cline { 2 - 4 } & 40 & $9.51 \%$ & $9.46 \%$ \\
\cline { 2 - 4 } & 60 & $9.59 \%$ & $9.57 \%$ \\
\hline
\end{tabular}

Fig 1. shows FTIR spectrum from empty fruit bunch, palm oil shell and biochar. The intensity of the peak which is around $\sim 3500 \mathrm{~cm}^{-1}$ shows stretching vibration of OH-bonds (alcohol, phenol, and carboxyl groups). The intensity of OH-bonds decreased after the hydrothermal process. It is due to dehydration of biomass occurred so that water molecules within the biomass removed [7].

The spectrum of aliphatic $(\mathrm{CH})$ groups present around $2900 \mathrm{~cm}^{-1}$. The intensity weakens after the hydrothermal process which indicates that several aliphatic chains are broke down during carbonization process [7]. The peak around $1600 \mathrm{~cm}^{-1}$ attribute to aromatic groups (lignin and aromatic groups) which is formed during carbonization [8]. The intensity around $1000 \mathrm{~cm}^{-1}$ shows CO-bonds whose intensity decrease after carbonization because of several CO-bonds are breakdown [8].
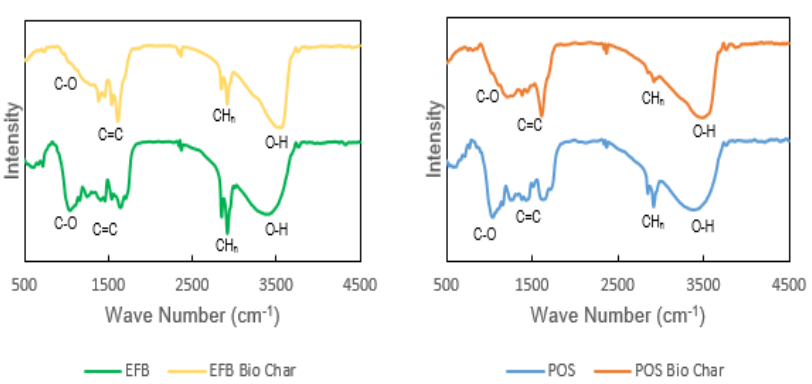

Fig 1. FTIR spectrum of empty fruit bunch, palm oil shell, and biochar

\subsection{Activation}

The BET surface area of activated carbon which is produced at different process parameters is shown in Table 3. The surface area of activated carbon sample for the biomass-to-water ratio (1:10) increase when holding time increase from 20 to 60 minutes. This may happen because some pores which are formed by the decomposition of organic components in materials increase when holding time of the hydrothermal process is longer. It makes the surface area of activated carbon increased after activation process. The interaction between $\mathrm{ZnCl}_{2}$ and biomass also more intense because of longer holding time during the hydrothermal carbonization. Moreover, $\mathrm{ZnCl}_{2}$ which acts as an activating agent removes the oxygen and hydrogen content in biomass by forming water and could enhance the porosity of the material [9].

The surface area of activated carbon sample increase for residence time 20 minutes whereas biomass-to-water ratio decrease. This may happen because of the concentration of $\mathrm{ZnCl}_{2}$ in the solution increase while biomass-to-water ratio decrease. Thus, the contact between $\mathrm{ZnCl}_{2}$ and biomass is more intense, and resulted the porosity of the activated carbon enhanced.

Table 3. Surface area of activated carbon $\left(\mathrm{m}^{2} / \mathrm{gr}\right)$

\begin{tabular}{|c|c|c|c|}
\hline \multirow{2}{*}{$\begin{array}{c}\text { Raw } \\
\text { Materials }\end{array}$} & \multirow{2}{*}{$\begin{array}{c}\text { Time } \\
(\mathrm{min})\end{array}$} & \multicolumn{2}{|c|}{ Biomass to water ratio } \\
\cline { 3 - 4 } & 20 & 330.52 & 1088.139 \\
\hline \multirow{3}{*}{ EFB } & 40 & 383.748 & - \\
\cline { 2 - 4 } & 60 & 644.146 & 1181.625 \\
\hline \multirow{3}{*}{ POS } & 20 & 17.008 & 451.862 \\
\cline { 2 - 4 } & 40 & - & 89.479 \\
\cline { 2 - 4 } & 60 & 221.407 & 7.679 \\
\hline \multicolumn{3}{|c|}{ Comercial activated carbon } & 832.967 \\
\hline
\end{tabular}

Average pore size diameter of activated carbon shown in Table.4. Activated carbon from empty fruit bunch and palm oil shell has mesopore size. The activated carbon from palm oil shell has bigger pore size than that from empty fruit bunch and has lower surface area than that from empty fruit bunch. Moreover, the surface area of activated carbon from palm oil shell for the biomass-to-water ratio (1:3) has no tendency increased with elevated residence time. These phenomena might be associated with the decreased solubility of $\mathrm{ZnCl}_{2}$ under subcritical conditions so that diminish its availability for chemical activation [10]. The different raw material which is used for activated carbon manufacturing has also affected the character of activated carbon characteristics [11].

Table 4. Activated carbon pore diameter (nm)

\begin{tabular}{|c|c|c|c|}
\hline \multirow{3}{*}{ Raw Materials } & \multirow{2}{*}{ Time (min) } & \multicolumn{2}{|c|}{ Biomass to water ratio } \\
\cline { 2 - 4 } & & $(1: 10)$ & $(1: 3)$ \\
\hline \multirow{3}{*}{ EFB } & 20 & 2.3686 & 2.1701 \\
\cline { 2 - 4 } & 40 & 2.12972 & - \\
\cline { 2 - 4 } & 60 & 2.232 & 2.3577 \\
\hline \multirow{3}{*}{ POS } & 20 & 12.4039 & 2.9098 \\
\cline { 2 - 4 } & 40 & - & 4.288 \\
\cline { 2 - 4 } & 60 & 3.128 & 5.541 \\
\hline \multicolumn{2}{|c|}{ Commercial activated carbon } & 2.29 \\
\hline
\end{tabular}

Average pore size of activated carbon from empty fruit bunch and palm oil shell is on the bottom range of mesopore size. This result affected by $\mathrm{ZnCl}_{2}$-to-raw material ratio. According to Ahmadpour and Do [12], 
$\mathrm{ZnCl}_{2}$-to-the raw material ratio which is used in this research drive the micro pore formation and pore widening simultaneously. Even though activated carbon has mesoporous size, it close to micro pore size.

Fig 2. shows the morphology of raw materials and activated carbon after hydrothermal carbonization and activation process. Fig $2 \mathrm{a}$ and $2 \mathrm{~b}$ indicate that both raw materials have a rough surface and closed pores. The morphology of empty fruit bunch and palm oil shell is developed after the heat treatment of hydrothermal carbonization and activation process. More pores are opened on biomass structure creating holes along the biomass surface, so that enhanced the porosity and increased the surface area of activated carbon.

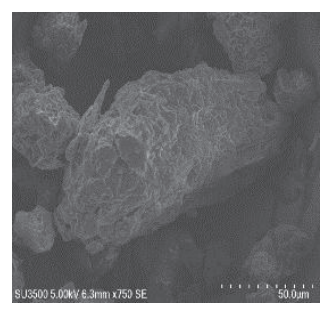

(a)

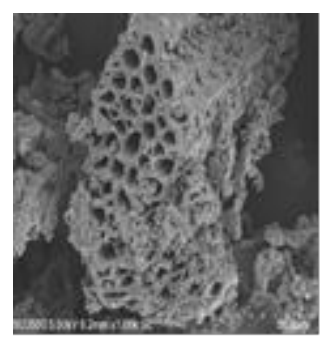

(c)

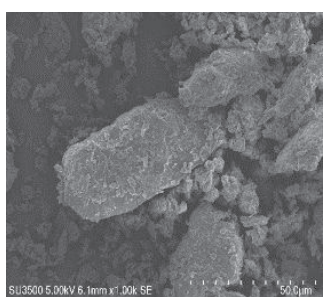

(b)

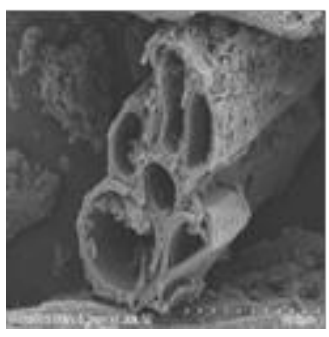

(d)
Fig 2. SEM result of: (a) empty fruit bunch; (b) palm oil shell; (c) empty fruit bunch activated carbon; and (d) palm oil shell activated carbon

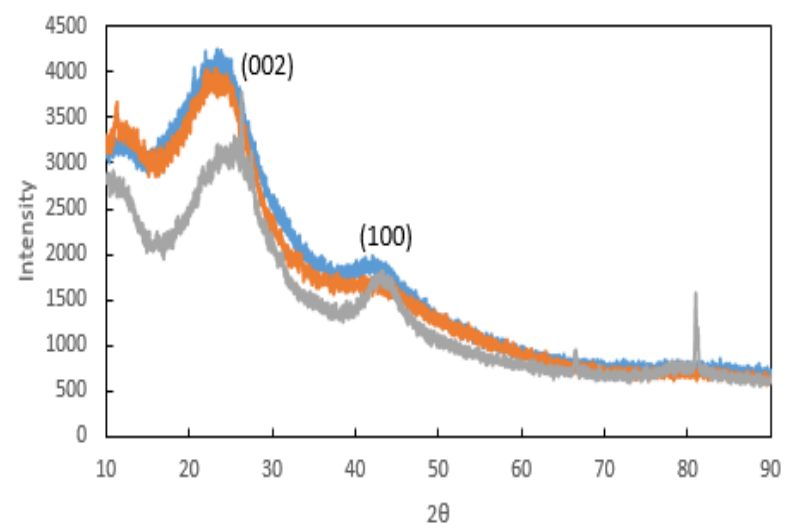

- EFB Activated Carbon —POS Activated Carbon - Comercial Activated Carbon

Fig 3. X-ray diffractogram of activated carbon

The peak from X-ray diffractogram indicates that carbon structure of activated carbon is still in amorphous phase. This phase is developed because of the destruction of initial graphite structure during carbonization and activation process. The peak between around $26^{\circ}$ and $40^{\circ}$ represent disorder carbon structure
(002) and (100). This carbon structure is intermediate structure between graphite and amorphous structure which is called turbostratic structure or random layered lattice structure [13]. This structure could be formed due to the presence of local stacking faults, random shifts between adjacent layers, varying interspacing values, unorganized carbons which are not a part of the layer structure, and strain in the layers [14].

\subsection{Electrochemical characterizations}

Electrochemical characterizations were conducted to analyze the performance of activated carbon while was applied in supercapacitor cell. Activated carbon which produced from empty fruit bunch (biomass-to-water ratio 1:10 and hydrothermal carbonization residence time 40 minutes) is used for this characterization.

Fig 4. shows the voltammogram of supercapacitor cell made by activated carbon produced and commercial activated carbon. The voltammogram has a tendency to form a slope and not in rectangular shape. This shape indicates charging-discharging process through high resistance inside the supercapacitor cell [15]. Moreover from the voltammogram it was suspected that corrosion reaction occurred in electrode due to the dielectric material used was too thin.

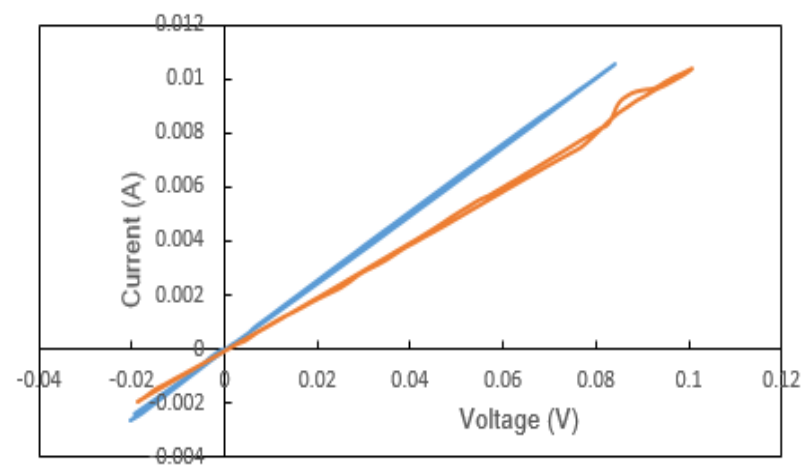

- Synthesized Activated Carbon Comercial Activated Carbon

Fig 4. Supercapacitor voltamogram

The specific capacitance of carbon electrode can be calculated from voltammogram according to the following formula [16].

$$
\mathrm{C}=\sum|\mathrm{I}| \cdot \Delta \mathrm{t} / \mathrm{m} \Delta \mathrm{V}
$$

where $\sum|\mathrm{I}| \cdot \Delta \mathrm{t}$ is the area of the current (A) against time $(\mathrm{s}) ; \mathrm{m}$ is the mass of active material in the electrode $(\mathrm{g})$; and $\Delta \mathrm{V}(\mathrm{V})$ is the potential window. Calculation of specific capacitance of carbon electrode shown in Table 5.

According to the capacitance calculation, it shows that the specific capacitance of synthesized activated carbon electrode is greater than commercial activated carbon electrode. The result of specific capacitance shows the contradiction to the surface area of commercial activated carbon. The capacitance is not affected by the surface area of materials. The lower specific capacitance of commercial activated electrode could be caused due to imperfect interphase connection 
and cell sealing system not optimal [17]. This imperfect cell sealing system could cause the presence of reactive and unstable oxygen functional groups which can interfere the ion transfer process [18]. This result also could be occurred by pore clogging due to some electrolyte ions trapped in the pore and causing the active site of activated carbon for ions storage decreased. In addition, side reactions between carbon, electrolyte and impurities could also decrease cell capacitance [19].

Table 5. Specific capacitance of carbon electrode

\begin{tabular}{|c|c|}
\hline Material & Capacitance (F/g) \\
\hline Synthesized activated carbon & 1.7554 \\
\hline Commercial activated carbon & 1.5107 \\
\hline
\end{tabular}

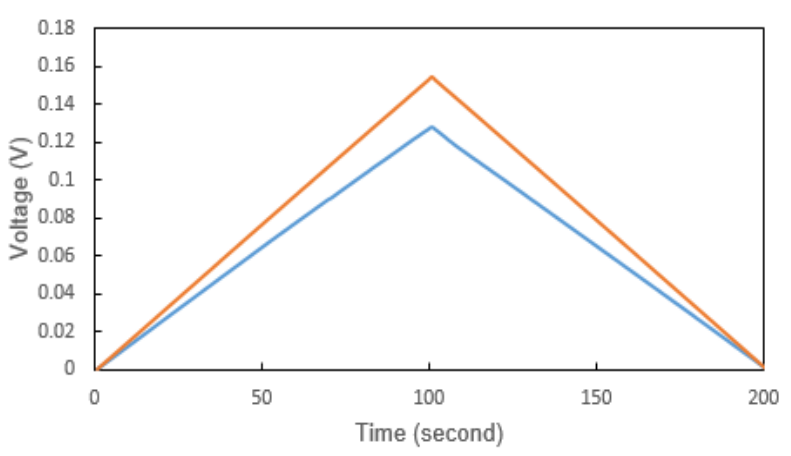

- Comercial Activated Carbon - Synthesized Activated Carbon

Fig 4. Galvanostatic charge/discharge (GCD) diagram.

Fig 4. shows galvano-static charge/discharge diagram (GCD) of synthesized activated carbon and commercial activated carbon electrode has a triangle and symmetric shape which indicate the supercapacitor cell has good capacitive performance [20]. The GCD of synthesized activated carbon electrode is greater than the that of the commercial activated carbon electrode. This result shows that the capacitance of supercapacitor cells made from synthesized activated carbon is greater than that of commercial activated carbon which is suitable with the results from calculations performed by cyclic voltammetry $(\mathrm{CV})$ analysis.

Electrochemical impedance spectroscopy (EIS) analysis was conducted to estimate the resistance of an electrochemical cell. The result of this analysis is represented in a Nyquist curve which is modelled with equivalent circuits to obtain the impedance value of the supercapacitor cell. The Nyquist curve and equivalent circuit are shown in Fig 5 and Fig 6 respectively.

The Nyquist curve of synthesized activated carbon supercapacitor has one semi circle curve which indicates cell impedance is affected by charge transfer. On the other hands, commercial activated carbon supercapacitor has two semi-circles curves which indicate cell impedance is not only affected by charge transfer but also mass transfer. Moreover, at the end of the semicircle from the Nyquist curve of commercial activated carbon supercapacitor has Warburg line that related to the diffusion layer.

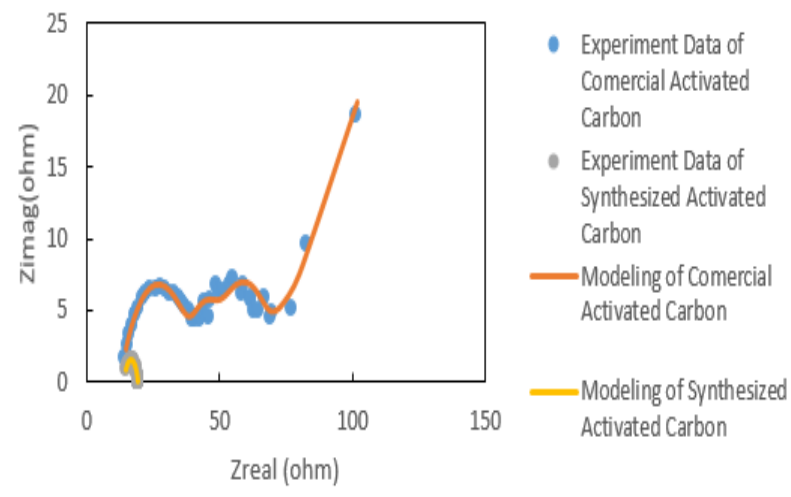

Fig 5. Nyquist curve.

(a)
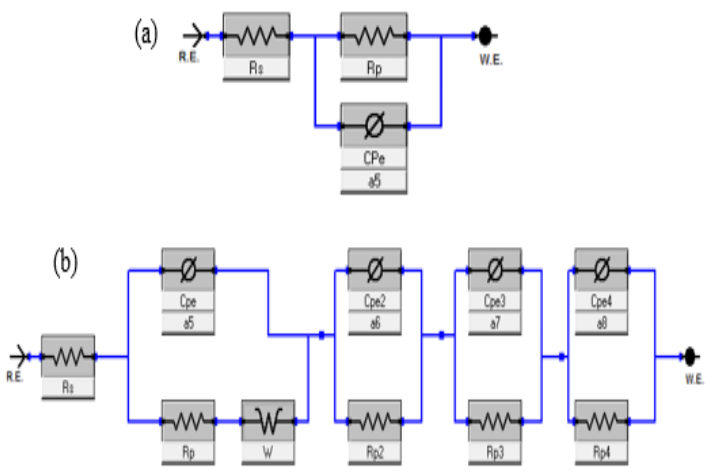

Fig 6. Equivalent circuit: (a) synthesized activated carbon supercapacitor and (b) commercial activated carbon supercapacitor.

Table 6. shows the parameters of the equivalent circuit modelling against the experimental data. Ohmic resistance (Rs) is a parameter which is related to the electrolyte resistance. Both of synthesized activated carbon and commercial activated carbon supercapacitor have a big ohmic resistance number and commercial activated carbon supercapacitor has greater interphase resistance (Rp) than the synthesized activated carbon supercapacitor. Moreover the ohmic and interphase resitance in this research was higher compared to the study conducted by Pramujo et al [17] which ohmic and interphase resistance generated from their supercapacitor cell were $4.9 \mathrm{ohm}$ and $5.4 \mathrm{ohm}$. This phenomenon might be happen due to the electrolyte dried rapidly because the sealing system was non-optimal. In addition the difficultness of electrolyte diffusion within the entire electrode surface made the both supercapacitor cell from present research have higher ohmic and interphase resistance [17]. Based on the EIS analysis, the interphase resistance of commercial activated carbon supercapacitor causes the capacitance of supercapacitor cell becomes smaller which is suitable with the results from calculations performed by cyclic voltammetry (CV) analysis. 
Table 6. Cell impedance (a) synthesized activated carbon supercapacitor (b) commercial activated carbon supercapacitor

(a)

\begin{tabular}{|c|c|c|}
\hline Parameter & Value & Unit \\
\hline $\mathrm{Rs}$ & 14.1 & $\mathrm{ohm}$ \\
\hline $\mathrm{Rp}$ & 5.3 & $\mathrm{ohm}$ \\
\hline $\mathrm{Cpe}$ & 0.000043 & $\mathrm{~S}^{*} \mathrm{~s}^{\wedge} \mathrm{a}$ \\
\hline $\mathrm{a} 7$ & 0.72 & \\
\hline
\end{tabular}

(b)

\begin{tabular}{|c|c|c|}
\hline Parameter & Value & Unit \\
\hline $\mathrm{Rp}$ & 4.527 & $\mathrm{ohm}$ \\
\hline $\mathrm{Rs}$ & 12.54 & $\mathrm{ohm}$ \\
\hline Cpe & 1.848 & $\mathrm{~S}^{*} \mathrm{~s}^{\wedge} \mathrm{a}$ \\
\hline $\mathrm{a} 5$ & 0.8134 & \\
\hline $\mathrm{W}$ & -0.506 & $\mathrm{~S}^{*} \mathrm{~s}^{\wedge}(1 / 2)$ \\
\hline Cpe2 & 0.000141 & $\mathrm{~S}^{*} \mathrm{~s}^{\wedge} \mathrm{a}$ \\
\hline $\mathrm{a} 6$ & 0.5693 & \\
\hline Rp2 & 27.93 & $\mathrm{ohm}^{\circ}$ \\
\hline Cpe3 & 0.02695 & $\mathrm{~S}^{*} \mathrm{~s}^{\wedge} \mathrm{a}$ \\
\hline $\mathrm{a} 7$ & 0.664 & \\
\hline Rp3 & 21.74 & ohm \\
\hline Cpe4 & 0.002883 & $\mathrm{~S}^{*} \mathrm{~s}^{\wedge} \mathrm{a}$ \\
\hline $\mathrm{a} 8$ & 0.8238 & \\
\hline Rp4 & 8.52 & ohm \\
\hline
\end{tabular}

\section{Conclusions}

Activated carbon as an electrode material of supercapacitor can be obtained from palm oil biomass waste through the hydrothermal carbonization and activation process. The capacitance of supercapacitor is $1.7754 \mathrm{~F} /$ gr. Decreasing biomass-to-water ratio, as well as increasing residence time during the hydrothermal carbonization process, could increase the surface area of activated carbon.

This work is supported by Badan Pengelola Dana Perkebunan Kelapa Sawit 2016.

\section{References}

1. R. C. Bansal, and M. Goyal, Activated carbon adsorption (Boca Raton, CRC Press ,2005)

2. E. Frackowiak, Q. Abbas, and F. J. Béguin, Energy Chem. 22(2), 226-240 (2013)

3. P. Basu, Biomass gasification and pyrolysis: practical design and theory (Academic press ,2010)
4. A. Jain, R. Balasubramanian, \& M. P. Srinivasan, Chem. Eng. J 283, 789-805 (2016)

5. K. Tekin, S. Karagöz, \& S. Bektaş, Renew. Sustainable Energy Rev. 40, 673-687 (2014)

6. A. C. Lua, F. Y. Lau, \& J. J. Guo, Anal. Appl. Pyrolysis 76(1), 96-102 (2006)

7. A. T. Yuliansyah, T. Hirajima, S. Kumagai, \& K. Sasaki, Waste Biomass Valori. 1(4), 395-405 (2010)

8. S. Nizamuddin, J. Kumar, N. Subramanian, J. N. Sahu, P. Ganesan, N. M. Mubarak, \& S. A. Mazari, Can. J. Chem. Eng. 93(11), 1916-1921 (2015)

9. A. Jain, S. Jayaraman, R. Balasubramanian, \& M. P. Srinivasan, J. Mater. Chem. 2(2), 520-528 (2014)

10. A. Jain, R. Balasubramanian, \& M. P. Srinivasan, Microporous Mesoporous Mater. 203, 178-185 (2015).

11. H. Marsh, and F. Rodriguez, Activated carbon (Elsevier Science \& Technology Books, 2006).

12. A. Ahmadpour, \& D. D. Do, Carbon 35 (12), 17231732 (1997).

13. B. Manoj, \& A. G. Kunjomana, Int. J. Electrochem. Sci 7(4), 3127-3134 (2012).

14. B. S. Girgis, Y. M. Temerk, M. M. Gadelrab, \& I. D. Abdullah, Carbon letters 8 (2), 95-100 (2007).

15. A. Thambidurai, J. K. Lourdusamy, J. V. John, and S. Ganesan, Korean J. Chem. Eng 31 (2), 268-275 (2014).

16. A. Elmouwahidi, Z. Zapata-Benabithe, F. CarrascoMarín, and C. Moreno-Casti, Bioresour. Technol. 111: $185-190$ (2012).

17. P. Widiatmoko, H. Devianto, I. Nurdin, and R. E. Yandra, J. Eng. Technol. Sci. 48 (5), 597-613 (2016)

18. W. Gu, N. Peters, and G. Yushin, Carbon 53: 292301 (2013).

19. D. Puthusseri, V. Aravindan, S. Madhavi, \& S. Ogale, Energy Environ. Sci. 7 (2), 728-735 (2014)

20. A. M. Abioye, Z. A. Noorden, \& F. N. Ani, Electrochim. Acta 225, 493-502 (2017) 